\title{
ATTITUDES OF GRADE ONE EDUCATORS TOWARDS THE IMPLEMENTATION OF INCLUSIVE EDUCATION IN CLASSROOMS AT BOTSHABELO SCHOOLS
}

\author{
Nomvuyo Joyce Mantshiyane ${ }^{1}$, Wendy Setlalentoa ${ }^{2}$, \& Pule Phindane ${ }^{3}$ \\ ${ }^{1}$ Department of Postgraduate Studies, Central University of Technology (South Africa) \\ ${ }^{2}$ Faculty of Humanities, Central University of Technology (South Africa) \\ ${ }^{3}$ Department of Languages and Social Sciences, Faculty of Humanities, Central University of Technology \\ (South Africa)
}

\begin{abstract}
The provision for learners with disabilities has been part of a process and the development of an inclusive education system can be traced back to the nation's founding document, the Constitution of the Republic of South Africa 108 of 1996. Creating an inclusive education environment is about celebrating diversity among learners and creating a welcoming culture where all learners are valued and made to feel that they belong. Inclusivity is about recognising that no two children are alike, and all children can learn. Most children with barriers to learning are accommodated in ordinary schools. Frequent causes of barriers to learning include discriminatory attitudes, labelling and discouragement. The study investigated Grade one educators' attitude towards the implementation of inclusive education at selected Botshabelo Primary Schools in the Free State Province. The study adopted an interactive qualitative approach. The population comprised educators and principals from selected primary schools in Botshabelo. A non-probability selection of participants was used to randomly select educators and principals from five schools. Data were analyzed by means of thematic analysis. The results of the study revealed that there are different factors contributing to the attitudes of Grade one educators towards the implementation of inclusive education in classrooms, amongst others, untrained educators for inclusive education; unsuitable environment for the disabled learners with learning barriers; lack of resources for inclusive education and curriculum at the level of learners with learning barriers; lack of parental involvement; and classroom overcrowding. The results revealed solutions to the negative attitudes of Grade one educators towards the implementation of inclusive education in classrooms which include training educators for inclusive education; parental involvement in learner's education; a suitable environment for disabled learners and those with learning barriers, consideration of learner-teacher ratio; availability of suitable resources for inclusive education; and availability of inclusive curriculum.

The study recommends that educators should be developed professionally by being trained about inclusive education; parents should be involved to support educators and their children; the school environment and buildings should be free from hazards; and overcrowding in classrooms should be avoided.
\end{abstract}

Keywords: Learning barriers, inclusive education, disability, educator, mainstreaming, attitude, inclusive, inclusion, curriculum.

\section{Introduction}

In 1994 democracy was established in South Africa, when there was a radical overhaul of government policy from an apartheid framework to providing services to all South Africans on an equitable basis. Learners with disabilities/ special needs and the development of an inclusive education system were included as part of the process. Learners with special needs are predominantly still in separate 'special' schools for learners with disabilities (Jordaan, 2015). South African inclusion initiatives that seek comparable learning models supported critical adaptation in the curriculum. Education systems had increased responsibility on the part of the teachers in learning styles to teach learners effectively by means of inclusive education models. Learners need to learn in ways that are accessible to them (Wildeman $\&$ Nomdo, 2007). Creating an inclusive education environment aims to celebrate diversity among learners and create a welcoming culture where all learners are valued and made to feel that they are acceptable. Inclusivity should recognise that no two children are the same and all children can learn. Children with learning disabilities should be accommodated at ordinary schools. The causes of learning barriers in learning include discriminatory attitudes, labelling and discouragement (Kratochvilova \& Havel, 2014). 


\section{Theoretical framework}

For this study to be coherent and focused, two social theories, namely Vygotsky's constructionist theories and Bandura's cognitive theories were used to support the data.

\subsection{Vygotsky 's theory on Social constructionist view of disability}

Vygotsky considered disability as a social aberration which springs from children 's changing social, environmental relations causing disturbances in social behaviour. According to Vygotsky (1993), cited by Rodina (2007), children with disabilities tend to have a special need for "detours" i.e. in other special educational environments (adapted educational milieu) and this milieu provides the necessary conditions for the cultural introduction of children with disabilities and realisation for mankind's inherent socio-cultural experience. Vygotsky stressed the importance of the distinction between primary and secondary developmental complications and succeeding symptoms in the study of upbringing, teaching, and education of children with different disabilities. Vygotsky (1993) indicated primary developmental complications as being primary deficient, which resulted from the very nucleus of directly interconnected deficiency and less subjected to remediation, while secondary developmental complications were social and psychological consequences of primary disabilities and less resistant to and more subjected to elimination.

Secondary disability can be prevented and eliminated by medical and educational means. Vygotsky (1993) stressed the importance of the dynamic, socio-cultural nature of disability for the methodology of inclusive education and importance of social learning in the upbringing and education of children with disabilities. According to Vygotsky, psychological-physical insufficiency was determined by a certain social setting, arrangement, or "aberration", hindering children's normal socialisation (cited by Rodina, 2007). Moore (2012) regards Vygotsky' s idea of learning and teaching as essentially social activities that take place between social actors in socially constructed situations. Both views suggest that Vygotsky's theory focused on interactions within classrooms where the teaching and learning process takes place (Botty \& Shahrill, 2014).

\subsection{Bandura's social cognitive theory}

The construct of self-efficacy had grown from the social cognitive theory of Bandura. Bandura defined self-efficacy expectation as the conviction of successfully executing the behaviour required to produce the outcomes (Bandura, 1977 cited by Scheer, Astrid, Scholz \& Donie 2015). Bandura (1997) cited by Sewel and St George (2000) regarded self-efficacy as judgement of one's ability to organise and execute given types of performance. Bandura (1982) cited, by Sewel and St George (2000) emphasised that the most effective way to create a strong sense of efficacy was through mastery experiences. Successful performance accomplishments provided the most authentic evidence of whether one had brought about success.

\subsection{Inclusive education}

Inclusive education is considered as a reform aimed to eliminate all barriers to the integration of children into the general education system, regardless of their differences and social background (Özokwu, 2018). Inclusive education requires a stimulating and responsive school environment that enables pupils to develop their inner potential, promoting their social corporation and guides them to corresponding future employment (Kratochvílová \& Havel, 2014).

\subsection{Inclusive schools}

The South African Education White Paper 6 (2001) defines an inclusive or full-service school as colleges, further and higher education institutions that are first and foremost mainstream education institutions that provide quality education to all learners by supplying the full range of learning needs in an equitable manner. Furthermore, with the introduction of the policy on Inclusive Education as published in Education White Paper 6 of 2001, the Department of Education made a commitment to ensure that all children are welcomed in all schools and that they would be supported to develop their full potential irrespective of their background, culture, abilities or disabilities, their gender or race. The concept inclusive or full-service school was introduced to show how ordinary schools could transform themselves becoming fully serviced schools.

Bhatnagar \& Das (2014) state that the regular classroom teacher is the single most important variable in the success of inclusion programmes. What they do and what they believe shape the quality of instruction that all learners, particularly those with disabilities, receive in the classroom. No matter how excellent the educational infrastructure might be, how well -articulated educational policy might be, how well- resourced a programme might be; effective inclusion does not take place until regular classroom 
teachers deliver relevant and meaningful instruction to learners with disabilities. Chakraborti-Ghosh (2017) poses that inclusive classrooms might contain several learners with special needs who have been mainstreamed full-time into the general classroom, or one or two learners who spend time each day in both a special educational classroom and a general classroom.

\section{Aim of the study}

The aim of the study was to investigate educators' attitude towards implementation of inclusive education at Botshabelo primary schools in the Free State Province.

\section{Research questions}

The study sought to answer the following questions:

$>$ Do grade one educators understand their duties towards the implementation of Inclusive Education and what views do they have on it?

Do Grade one educators get professional development on Inclusive Education?

\section{Research methodology}

In this study interactive qualitative research was carried out. It was the research method used in the interviews (Kumar, 2014). According to McMillan and Schumacher (2014), qualitative techniques or interactive qualitative research collect data primarily in the form of words rather than numbers. Qualitative techniques provide verbal descriptions, portraying richness and complexity of events that occur in natural settings from participants' perspectives. The qualitative data were collected by means of interviews with Grade one educators of inclusive education and School Management Teams (SMT) at selected Botshabelo primary schools.

\subsection{Population and sampling}

The research population consisted of three educators from each of the randomly selected schools offering inclusive education in Botshabelo.

The method that was applied involved non-probability sampling. As sample of two schools was drawn and selected randomly. Two schools from Section F and Section K were selected were selected, respectively. The researcher distributed questionnaires and interviewed the Grade one educators who were information-rich participants in inclusive education, as well as the Site-Based Support Team (SBST).

\subsection{Data analysis}

The study was essentially qualitative; therefore, the analysis of data gathered was equally qualitative. The educators' responses to the questions, the behaviour, utterances, as well as perceptions of all informants and observations conducted were recorded and noted down, and collectively assessed against the generally accepted behaviour, attitude, and requirements of inclusive education in the classroom.

\section{Results}

When asked about inclusive education the teachers seemed to know exactly what it entails as well as the role they are expected to play. The results also revealed that the socio-economic background of learners; under- resourced, overcrowded classrooms, parents, school, and the community contributed to the attitudes of Grade one educators on Inclusive classrooms at selected schools in Botshabelo. Educators expressed concerns on having stress and anxiety when including learners with barriers.

Quoted verbatim Educator Z "All learners are capable of learning even if they are challenged".

Educator X: "Our classes accommodate all learners in the mainstream, quite often, the physical resources are a problem"

The negative attitudes of educators regarding the Implementation of Inclusive Education in classrooms contribute to the problems encountered by inclusive education. The success of inclusive education relies on the success of teachers in learning skills and perspectives assumed by new visions of inclusion and unlearning practices and beliefs with regards to learners and instruction that dominated their professional lives up to this moment. According to Chander (2016) attitudes of educators to the successful 
implementation of inclusive education vary from one person to another and they played an important role in determining how people react to a situation and help to predict human behaviour.

Most educators have problems in implementing inclusive education in classrooms.

Educator W indicated that: "Our school is not developed to accommodate disabled learners. Also, we do not get support from some parents. How can I perform?"

Educator Z: "Some parents at times interfere and want to tell us how we should treat and teach learners in our classes"

Educator U: "Our classrooms are crowded. This makes it practically impossible to accommodate learners with special needs in teaching and learning".

Effectively the inclusion of children with special educational needs in the classroom was a crucial goal as it provided important factors that helped them to adapt, i.e., being taught together with other children, feeling part of the class, and being recognized by it, with the resources it furnishes and the issues it entails (Ainscow, Booth \& Dyson, 2006 by cited Santos, Sardinha \& Reis 2016). Without sufficient resources, the work of the educator becomes difficult. Research that involved principals in schools in Gauteng, the richest and best resourced province of South Africa, also determined that disabled learners received specialised support services either "seldom" or "never" (Nel, Muller \& Rheeders, 2011). The study indicated that successful Implementation of Inclusive Education mainly depends on the positive attitude of educators.

Nine of the ten teachers interviewed indicated that they attended workshops on inclusive education, however, Educator Y further stated that:

"Yes, even though workshops have been organised for us, but I think they were not enough, I still am not confident enough to teach learners with challenges regarding learning".

The study indicated that lack of training of educators constitute a key problem and the most crucial obstacle that hampers policy makers' endeavour to establish Inclusive Education successfully. It is important to take into cognisance that more support needs to be given to educators even after workshops. The attitude of Grade one educators on Inclusive Education Implementation in classrooms at Botshabelo can be attributed to lack of training of educators. Educators have a vital role to play in the successful Implementation of Inclusive Education.

\section{Conclusion}

The need of support for educators is often overlooked, this contributes to anxiety on their part and the barriers to successful inclusive education. Lack of differentiation in instruction and pressure put by parents of learners without special needs also contributes to the attitudes of Grade one educators on Inclusive Education Implementation. Educators who are already overworked and overstrained experience additional pressure from parents who do give support to their own children. Parents should also ensure that learners with special needs are supported and treated with respect by their peer group and teachers.

\section{References}

Bhartnagar, N. 2014. Regular schoolteachers' concerns and perceived barriers to implement inclusive education in New Delhi, India. International Journal of Instruction, 7(2): 89-102.

Booty, H. M.R.H. \& Shahrill, M. 2014. The impact of Gagné, Vygotsky and Skinner theories in pedagogical practices of Mathematics teachers in Brunei Darussalam. Review of European Studies, 6(4): 100-109.

Chander, R. 2016. Attitudes of teachers and students towards mainstreaming, Indian Journal of Health and Wellbeing, 7(1):101-1-5.

Chankraborti-Ghosh, S. 2017. Inclusive education in India: a developmental milestone from segregation to inclusion. Journal of Educational Systems. 1(1): 53-62.

Department of Education. 2001. White Paper 6: Special Needs Education-Building an inclusive education and training system. Pretoria: Department of Education. Available http://www.education.gov.za/LinkClick.aspx?fileticket=gVFccZLi/tl=\&tabit=191\&mid=484. (Accessed 06/11/2017).

Grant, C. \& Osanloo, A. 2014. Understanding, selecting, and integrating a theoretical framework in dissertation research: creating the blueprint for your "house". Administrative Issues Journal, 4(2): 12-16.

Jordaan, A. 2015. Inclusive education in South Africa: the good, bad and ugly. Accessed from: http://news.nwu.ac.za/inclusive-education-south-africa-good-bad-and-ugly 
Kumar, R. 2014. Research methodology: a step-by-step guide for beginners. $4^{\text {th }}$ ed. California: Sage Publications.

McMillan, J.H. \& Schumacher, S. 2014. Research in education: evidence-based inquiry. $7^{\text {th }}$ ed. New York: Pearson Education Limited.

Moore, A. 2012. Teaching and learning. $2^{\text {nd }}$ ed. London: Routledge.

Nel, N., Muller, H. \& Rheeders, E. 2011. Support services within inclusive education in Gauteng: The necessary and efficiency of support. International Journal of Education, 1(1):38-53.

Özokwu, O. 2018. The relationship between teacher attitude and self-efficacy for inclusive practices in Turkey. Journal of Education and Training Studies, 6(3): 6-12.

Rodina, K.A. 2006. Vygotsky's social constructionist view on disability: a methodology for inclusive

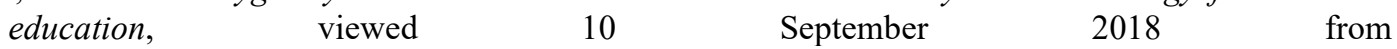
http://lchc.ucsd.edu/mca/Paper/VygotskyDisabilityEJSNE2007.pdf

Santos, G.D., Sardinha, S. \& Reis, S. 2016. Relationships in inclusive classrooms. Journal of Research in Special Educational Needs, 16(1): 950-954.

Scheer, D., Scholz, M., Rank, A., \& Donie, C. (2015). Inclusive beliefs and self-efficacy concerning inclusive education among German pre-service teachers. Journal for Cognitive Education and Psychology, 14 (3): 270-293.

Sewell, A. \& St George A. 2000. Developing efficacy beliefs in the classroom. Journal of educational enquiry, 1 (2): 58-71.

Wildeman, R.A. \& Nomdo, C. 2007. Implementation of inclusive education: how far are we? Occasional Paper, IDASA: Pretoria. 